\begin{tabular}{lrr}
\hline Volume 22 & Nomor 1, Januari 2021 & Halaman 1-10 \\
URL: https://jurnal.unej.ac.id/index.php/SEMIOTIKA/index & E-ISSN: 2599-3429 & P-ISSN: 1411-5948 \\
\hline
\end{tabular}

\title{
BIAS PATRIARKI DI BALIK PELAKSANAAN TRADISI TUNDUAK DI MINANGKABAU
}

\author{
PATRIARCHY BIAS BEHIND THE PRACTICE OF TUNDUAK TRADITION \\ IN MINANGKABAU
}

\author{
Silvia Rosa* \\ Fakultas Ilmu Budaya Universitas Andalas, Padang \\ *Corresponding Author: silviarosa@hum.unand.ac.id \\ Informasi Artikel: \\ Dikirim: 18/5/2020; Direvisi: 21/11/2020; Diterima: 5/1/2021
}

\begin{abstract}
In Minangkabau society, the Tunduak is a tradition when the newly marriage visits father in law's house for the first time. This article aims to discuss the meaning of implementing the Tunduak Tradition carried out by the bride in Solok Regency, West Sumatra Province. The research method used is a cognitive semiological methods. Data were collected through field surveys in photographs and words or narration obtained through audio and visual recording techniques. Data analysis was performed using the semiotic theory of myth by Rolland Barthes. The implementation of this tradition is accompanied by members of the bride's relatives who come with various kinds of luggage to be presented to the groom's relatives. The study results show that the implementation of the Tunduak Tradition in the view of the Minangkabau custom in Solok Regency gives its characteristics in Minangkabau customs' performance. Namely the accompaniment of the group's configuration walking to the house of the bride's parents-in-law while carrying the luggage placed on the head, and only done by the woman's close relatives of the bride. It reflects a cultural parade that can be used as an exciting spectacle in various areas in Solok Regency. The study results concluded that the implementation of the Tunduak Tradition represents an institutionalized myth to glorify the position and position of men in the matrilineal society in Minangkabau.
\end{abstract}

Keywords: Barthes, Minangkabau, women, semiotics, Tunduak Tradition

Abstrak

Dalam masyarakat Minangkabau dikenal Tradisi Tunduak, yakni tradisi berkunjung ke rumah mertua laki-laki untuk pertama kalinya bagi pasangan yang baru menikah. Artikel ini bertujuan mendiskusikan makna pelaksanaan Tradisi Tunduak yang dilakukan oleh mempelai perempuan di Kabupaten Solok, Provinsi Sumatera Barat. Metode penelitian yang digunakan adalah metode semiologi kognitif. Data dikumpulkan melalui survei lapangan dengan unit data berupa foto-foto dan kata-kata atau narasi yang diperoleh melalui teknik perekaman audio dan visual. Analisis data dilakukan dengan menggunakan teori semiologi tentang mitos oleh Rolland Barthes. Pelaksanaan tradisi ini diiringi oleh anggota kerabat mempelai perempuan yang datang membawa aneka macam barang bawaan untuk dipersembahkan kepada kerabat mempelai lelaki. Hasil kajian menunjukkan bahwa pelaksanaan Tradisi Tunduak dalam pandangan adat Minangkabau yang berlaku di Kabupaten Solok memberikan ciri khas tersendiri dalam pelaksanaan adat istiadat Minangkabau, yaitu berupa iringan konfigurasi barisan rombongan yang berjalan kaki menuju rumah mertua mempelai perempuan sambil membawa barang bawaan 
diletakkan di atas kepala, dan hanya dilakukan oleh para perempuan kerabat dekat mempelai perempuan. Hal tersebut mencerminkan parade budaya yang dapat dijadikan tontonan menarik di berbagai wilayah di Kabupaten Solok. Hasil kajian menyimpulkan bahwa pelaksanaan Tradisi Tunduak merepresentasikan sebuah mitos yang melembaga untuk memuliakan posisi dan kedudukan lelaki dalam masyarakat matrilineal di Minangkabau.

Kata kunci: Barthes, Minangkabau, perempuan, semiologi, Tradisi Tunduak

\section{PENDAHULUAN}

Sistem perkawinan di Minangkabau bersifat eksogami dan endogami. Perkawinan ideal diharapkan terjadi antara dua orang individu yang berbeda nama suku ibunya dan sekaligus berada di dalam nagarinya. Sebagai contoh, seorang perempuan bersuku Caniago diatur agar tidak menikah dengan lelaki yang juga bersuku Caniago, melainkan memilih lelaki yang memiliki nama suku selain nama suku Caniago, demikian juga sebaliknya. Aturan yang bersifat eksogami (keluar suku) ini dianut demi mempertimbangkan agar perkawinan tidak terjadi antara individu yang masih memiliki kedekatan hubungan darah. Darussalam (2017) menyatakan bahwa terdapat sisi negatif dan positif melakukan pernikahan antara kerabat sendiri. Secara sains disebutkan bahwa perkawinan dengan anggota kerabat dekat dapat memunculkan karakter resesif yang menimbulkan kelemahan pada keturunan kelak (Darussalam, 2017).

Adat Minangkabau mengatur bahwa orang yang masih dekat hubungan darahnya adalah bersaudara, tidak jarang mereka berasal dari satu suku yang sama. Prinsip hubungan darah yang dimaksudkan ini adalah hubungan darah berdasarkan prinsip kekerabatan matrilineal, meskipun agama mayoritas yang dianut oleh orang Minangkabau adalah agama Islam, namun prinsip kerabat mengacu pada garis perempuan (matrilineal). Selain aturan menikah dengan indivudu di luar nama sukunya, seorang individu dianjurkan menikah dengan individu lain yang berasal dari nagari yang sama (kampungnya). Prinsip ini dikenal dengan istilah endogami. Kriteria endogami mempunyai batasan yang berbeda-beda pada tiap kelompok masyarakat. Bagi orang Minangkabau kriteria endogami adalah nagari, jadi menikah dengan orang sesama dalam nagari dianjurkan, namun berasal dari nama suku yang berbeda.

Kriteria endogami pada kelompok masyarakat lain dapat juga berupa kasta, suku, agama, dan kriteria lainnya (Darussalam, 2017); ada juga yang memakai kriteria kemurnian nasab secara Islam (Azhari, Muttaqien, \& Kurdi, 2013); sebagaimana juga terjadi dalam masyarakat Tengganana di Bali (Parwesi, 2012; Wardani, Pursika, \& Adnyani, 2013).

Prinsip endogami ini tidak terlalu kuat mengikat orang Minangkabau karena perkawinan dengan orang yang tidak sama asal nagarinya juga kerap dilakukan oleh orang Minangkabau, asalkan berbeda suku dengan dirinya. Prinsip endogami ini merupakan wujud dari keinginan untuk menjaga kemurnian ikatan kekeluargaan dalam satu nagari yang sama, tidak berbeda jauh dengan alasan perkawinan endogami di Sidigede, Jepara (Nuryani, 2012). Meskipun pernikahan dilakukan dengan orang dalam satu nagari yang sama, tetapi mereka sudah tidak satu suku lagi. Alasannya, karena dalam satu nagari minimal sudah ada empat macam suku yang berbeda. Kondisi ini sebagai dampak dari persyaratan berdirinya sebuah 
nagari dalam aturan adat Minangkabau adalah sebuah kawasan yang penduduknya sudah dihuni oleh minimal empat macam nama suku yang berbeda. Artinya, berdasarkan aturan minimal pendirian sebuah nagari yang terdiri atas empat nama suku ini telah mengindikasikan bahwa orang yang berdomisili dalam satu nagari yang sama sudah berbeda-beda juga lingkaran kekerabatan matrilinealnya. Setiap lingkaran kekerabatan itu biasanya dikepalai oleh seorang kepala suku yang disebut jabatannnya sebagai penghulu suku. Dengan demikian, tentu sudah ada minimal empat penghulu suku yang memimpin kaumnya dalam satu nagari di Minangkabau.

Aturan perkawinan yang bersifat endogami tidak terlalu kaku mengikat tata krama memilih jodoh dalam aturan adat Minangkabau, namun tidak demikian halnya dengan aturan yang bersifat eksogami terdahulu. Aturan eksogami masih dianut oleh masyarakat Minangkabau hingga saat kini (Asmaniar, 2018); tidak hanya di daerah rantau (Putriyah, 2016); tetapi juga tetap dipatuhi aturan ini di daerah darek (Herviani, 2019). Apabila ada individu yang melanggar aturan ini maka individu tersebut akan terkena denda adat dan peristiwa demikian bukanlah yang dicita-citakan oleh sebuah kaum maupun individu di Minangkabau. Denda itu dapat berupa sanksi dibuang sepanjang adat dari kampung (Khairani \& Fitriani, 2020). Apalagi terhadap orang yang melanggar ketentuan adat tersebut juga berlaku sanksi sosial, yaitu diabaikan dari pergaulan sosial masyarakat. Hal ini adalah denda terberat yang dialami oleh seorang individu dan kaum kerabat jika anggota keluarganya melakukan pelanggaran aturan perkawinan yang bersifat eksogami.

Konsekuensi dari ketentuan yang berlaku dalam perkawinan di Minangkabau ini, maka pelaksanaan perkawinan menjadi kerja kolektif, kerja kaum kerabat. Individu yang menikah tidak dapat bersikeras melakukan kehendak dan kemauan sendiri dalam pelaksanaan prosesi perkawinannya. Kaum kerabat akan menguruskan semua prosedur pelaksanaan prosesi perkawinan seorang anak dan kemenakannya. Kerabat yang paling aktif memegang peranan dalam persiapan dan pelaksanaan perkawinan seorang anak dan kemenakan dalam masyarakat Minangkabau adalah ninik mamak dan induak bako.

Ninik mamak adalah kumpulan para lelaki yang bersaudara dengan ibu seorang ego yang menjadi mempelai, sementara induak bako adalah kumpulan kerabat perempuan yang bersaudara dengan ayahnya. Pihak ninik mamak dan induak bako merupakan kedua kerabat yang paling sibuk mengurusi persiapan dan pelaksanaan perkawinan seorang anak dan atau kemenakan yang akan menikah. Kesibukan yang melanda kedua belah pihak ini tidak terkait dengan urusan materi karena hal itu menjadi beban utama kedua orang tua mempelai. Namun kesibukan mereka terkait tugas-tugas adat istiadat yang bersifat kolektif yang dimaksudkan untuk menjaga harga diri kerabat. Ninik mamak menjadi orang yang disegani dan diajak berunding ketika dilakukan permusyawarahan untuk mencapai kesepakatan terkait ketentuan dalam pelaksanaan prosesi perkawinan, demikian juga halnya dengan induak bako. Salah satu kegiatan dalam prosesi perkawinan yang melibatkan kedua belah pihak ini adalah pelaksanaan Tradisi Tunduak bagi orang Solok di Minangkabau.

Tradisi Tunduak berlangsung di daerah Solok (Rosa, Gayatri, Awwali, Hasanuddin, \& Anwar, 2010), yaitu suatu kawasan georafis kultural yang berada di luar wilayah inti Minangkabau. Secara tradisional, wilayah kultural di Minangkabau terbagi dua, yaitu kawasan wilayah Luhak Nan Tigo, seringkali juga disebut sebagai wilayah darek Minangkabau yang sekaligus menjadi wilayah inti adat istiadat Minangkabau, dan wilayah 
rantau, yaitu selain dari wilayah Luhak Nan Tigo tersebut yang juga merupakan kawasan pengembangan (koloni) dari wilayah Luhak Nan Tigo tersebut. Sementara, Solok tidak termasuk ke dalam kedua kawasan tersebut. Solok masuk suatu kawasan yang disebut sebagai ikua darek kapalo rantau (ekor bagian darek, sedangkan kepala termasuk rantau). Artinya, daerah Solok tidak menjadi bagian kawasan darek namun juga tidak menjadi bagian kawasan rantau. Solok memiliki daerah otoritas dan kekhasan tersendiri. Kekhasan dan otorisasi yang dimiliki oleh daerah Solok tersebut, menyebabkan adat dan budaya di Solok memiliki kekhasannya pula, terutama terkait dengan pelaksanaan Tradisi Tunduak. Tradisi ini hanya berlangsung di Solok, dan prosesinya berlangsung unik dan menarik.

Artikel ini membahas makna pelaksanaan Tradisi Tunduak yang dilakukan oleh mempelai perempuan di Solok. Pemaknaan dimaksudkan untuk memahami aspek simbolik yang bertebaran di seputar pelaksanaan tradisi yang dilakukan oleh mempelai perempuan dan karib kerabatnya. Perspektif semiologi Roland Barthes menjadi pilihan yang digunakan untuk membantu kerangka berpikir dalam menganalisis tanda-tanda budaya dalam pelaksanaan Tradisi Tunduak. Semiologi Barthes merupakan sebuah perspektif ilmu terkait tanda-tanda yang memposisikan tuturan sebagai sebuah fenomena yang mengandung sebuah gagasan ideologis. Barthes (1993) menyatakan bahwa sebuah tuturan ketika selalu diulang-ulang, dipilih oleh sejarah dan digunakan secara sosial, tuturan itu akan menjadi bersifat mitologis. Tuturan itu dapat berupa pertunjukan, penayangan, iklan, film, fotografis, dan teks-teks budaya lainnya (Barthes, 1993).

Bersandar pada perspektif teoretik Barthes ini fenomena tanda yang berseliweran dalam pelaksanaan Tradisi Tunduak dimaknai. Penelitian terkait dengan topik ini belum ditemukan sejauh pengamatan dan pembacaan yang berhasil dilakukan, kecuali sebuah buku yang berisi deskripsi tentang adat dan budaya kota Solok (Rosa et al., 2010), salah satunya yang terkait dengan Tradisi Tunduak.

\section{METODE}

Penelitian ini dilakukan dengan menggunakan metode semiologi kognitif, dengan data bersumber dari kegiatan pelaksanaan Tradisi Tunduak yang dilakukan oleh masyarakat Solok di Minangkabau. Data dikumpulkan melalui kegiatan survei lapangan yang hasil deskripsinya sudah dituliskan dalam buku yang ditulis oleh Rosa, et al. (2010).

Deskripsi tertulis terkait pelaksanaan Tradisi Tunduak itu menjadi objek material yang dimaknai secara semiologis dalam artikel ini. Hasil survei yang telah didokumentasikan dalam bentuk visual, dan dokumentasi isi yang diperoleh dari hasil wawancara dengan responden, digunakan sebagai unit data yang hendak dianalisis dalam kajian ini. Analisis data dilakukan dengan berpijak pada perspektif semiologi Rolland Barthes.

\section{HASIL DAN PEMBAHASAN}

Hasil

Tradisi Tunduak menjadi ciri khas adat dan budaya orang Solok di Minangkabau. Kekhasan tradisi ini tampak jelas terpampang apabila kita melewati daerah Solok pada harihari pelaksanaan tradisi tersebut. Tradisi ini tampak sebagai sebuah parade budaya jika kebetulan kita melewati rombongan yang sedang melaksanakan Tradisi Tunduak di pinggir jalan kota Solok. Gambar 1 berikut ini memperlihatkan sebuah rombongan Tradisi Tunduak 
yang sedang dalam perjalanan menuju rumah yang akan dituju. Tradisi ini dilaksanakan oleh mempelai perempuan dan kerabatnya ke rumah mertuanya dengan cara berjalan kaki menyusuri tepi jalan menuju rumah mertua dari mempelai perempuan.

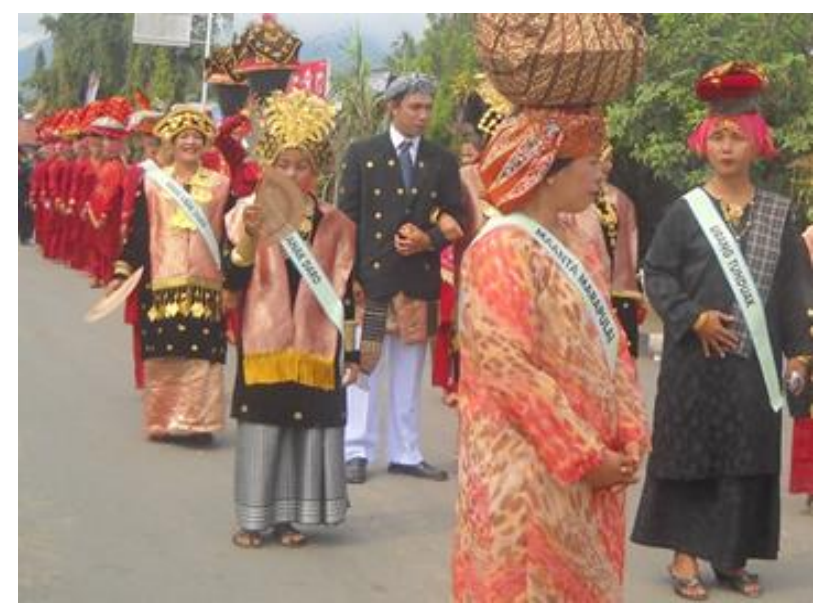

Gambar 1. Rombongan mempelai perempuan yang sedang melaksanakan Tradisi Tunduak di Solok, Sumatera Barat.

Foto: Koleksi Silvia Rosa

Keunikan pelaksanaan tradisi ini tampak pada konfigurasi barisan kerabat karib yang terlibat dalam pelaksanaan Tradisi Tunduak. Semua kerabat perempuan dari mempelai perempuan, biasanya terdiri atas induak bako dan para istri ninik mamak berbaris satu banjar memanjang ke belakang. Iring-iringan ini tampak unik dan khas karena konfigurasi barisan yang mereka bentuk, yaitu hanya satu barisan panjang. Rombongan tradisi ini berjalan kaki menyusuri tepi jalan menuju rumah mertua si mempelai perempuan. Tradisi ini dilaksanakan sehari setelah pesta perkawinan usai.

Pada gambar 3 tampak seorang perempuan mengenakan baju hitam yang berdiri paling depan dari konfigurasi barisan. Perempuan berbaju hitam yang berdri pada barisan terdepan tersebut adalah orang yang disebut sebagai Tuo Tunduak. Perempuan yang bertugas sebagai Tuo Tunduak menjadi penanggung jawab kelancaran prosesi pelaksanaan Tradisi Tunduak. Tugas dan tanggung jawab yang besar dan berat dibebankan kepada Tuo Tunduak. Apabila terjadi kesalahan dan kejanggalan dalam pelaksanaan Tradisi Tunduak maka yang paling dahulu dimintai pertanggungjawabannya adalah dirinya. Tuo Tunduak menjadi wakil kerabat mempelai perempuan dalam pelaksanaan Tradisi Tunduak tersebut, biasanya dipilih seorang perempuan yang dipandang paling mampu memikul tanggung jawab kerabat, pandai berbicara dalam bahasa adat, arif, dan bijaksana. Tuo Tunduak bertugas membawa sebuah kampia siriah (tempat sirih).

Pada gambar 2 berikut ini, tampak seorang Tuo Tunduak yang sedang membawa kampia siriah yang dibungkus kain berwarna merah dan diletakkan di atas kepalanya. 


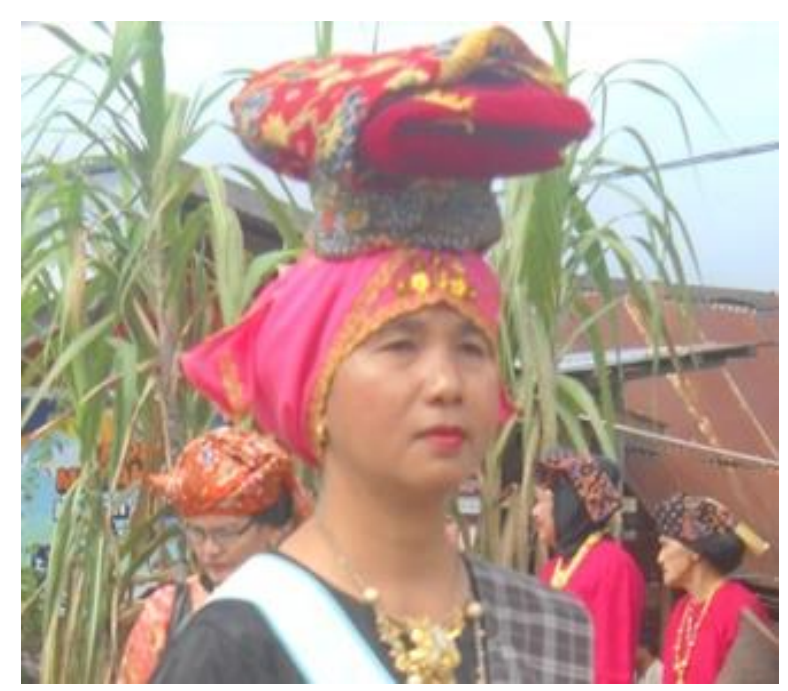

Gambar 2. Perempuan yang bertugas sebagai Tuo Tunduak membawa kampia siriah di atas kepalanya. Foto: Koleksi Silvia Rosa

Konfigurasi barisan rombongan Tradisi Tunduak ini biasanya terdiri atas 7, 9, atau paling banyak sampai 11 orang. Keputusan tentang jumlah perempuan pengiring mempelai dalam pelaksanaan Tradisi Tunduak sangat bergantung pada hasil perundingan kerabat sebelumnya dan juga dipengaruhi oleh kadar atau jenis alek (pesta adat) yang dilaksanakan. Kadar atau jenis alek yang dimaksdukan adalah besar kecilnya pesta adat yang dilaksanakan oleh kerabat mempelai perempuan.

Apabila jenis alek yang dipilih adalah alek pucuak rabuang atau kabuang ketek, maka jumlah perempuan pengiringnya hanya 7 orang. Alek pucuak rabuang adalah alek biasa. Apabila jenis alek yang dipilih adalah alek gulai manih dan alek jamba gadang, maka jumlah perempuan pengiringnya adalah 9 orang. Alek gulai manih dan alek jamba gadang adalah jenis pesta adat yang ruang lingkup undangan dan juga bentuk hidangan yang disediakan sudah jauh lebih besar dibandingkan dengan alek pucuak rabuang. Akan menjadi bertambah banyak jumlah perempuan pengiringnya menjadi dua kali lipat, yaitu dua kali 11 menjadi 22, apabila alek yang dilaksanakan oleh kerabat perempuan adalah alek batonjong (pesta adat yang paling besar, biasanya mempelai berasal dari keturunan raja-raja). Jenis pesta adat yang terakhir ini sudah jarang sekali dilakukan saat ini.

Perempuan dalam barisan yang panjang itu berjalan kaki sambil membawa katidiang hitam (bakul berwarna hitam) yang diletakkan di atas kepalanya. Katidiang hitam itu berisi berbagai macam aneka bawaan dan hantaran mempelai perempuan untuk mertuanya. Barang yang dibawa dalam katidiang hitam itu biasanya berupa nasi dan lauk pauk, makanan dan kue-kue tradisional Minangkabau dan kado. Semua isi katidiang hitam adalah persembahan mempelai perempuan kepada mertuanya.

Para perempuan pengiring mempelai perempuan dalam pelaksanaan Tradisi Tunduak berasal dari kerabat perempuan pihak ibu yang berposisi sebagai istri mamak, istri saudara kandung seibu, istri saudara seayah, induak bako, anak pisang, maupun para tetangga perempuan terdekat dengan ibu mempelai perempuan. Semua perempuan pengiring mempelai perempuan membawa beban katidiang hitam di atas kepalanya. Barisan panjang itu dipimpin paling depan oleh Tuo Tunduak, yang kemudian diikuti oleh sepasang mempelai. 
Di belakang mempelai berbaris para kerabat perempuan yang diurutkan sesuai posisi kedekatannya dengan mempelai perempuan. Posisi nomor tiga, tepat di belakang mempelai perempuan biasanya ditempati oleh para istri mamak, diikuti oleh posisi keempat dan kelima oleh induak bako, di belakangnya pada urutan nomor enam dan tujuh para sumandan, sedangkan pada posisi nomor delapan dan sembilan adalah pihak anak pisang dan tetangga terdekat dengan ibu mempelai perempuan. Semua barisan itu berjumlah sembilan orang memanjang ke arah belakang kedua mempelai. Namun, apabila jenis alek yang dilaksanakan adalah jenis alek jamba gadang maka rombongan itu akan berjumlah sebelas orang.

Gambar 3 berikut ini memperlihatkan barisan para perempuan pendamping mempelai perempuan dalam melaksanakan Tradisi Tunduak ke rumah mertuanya.

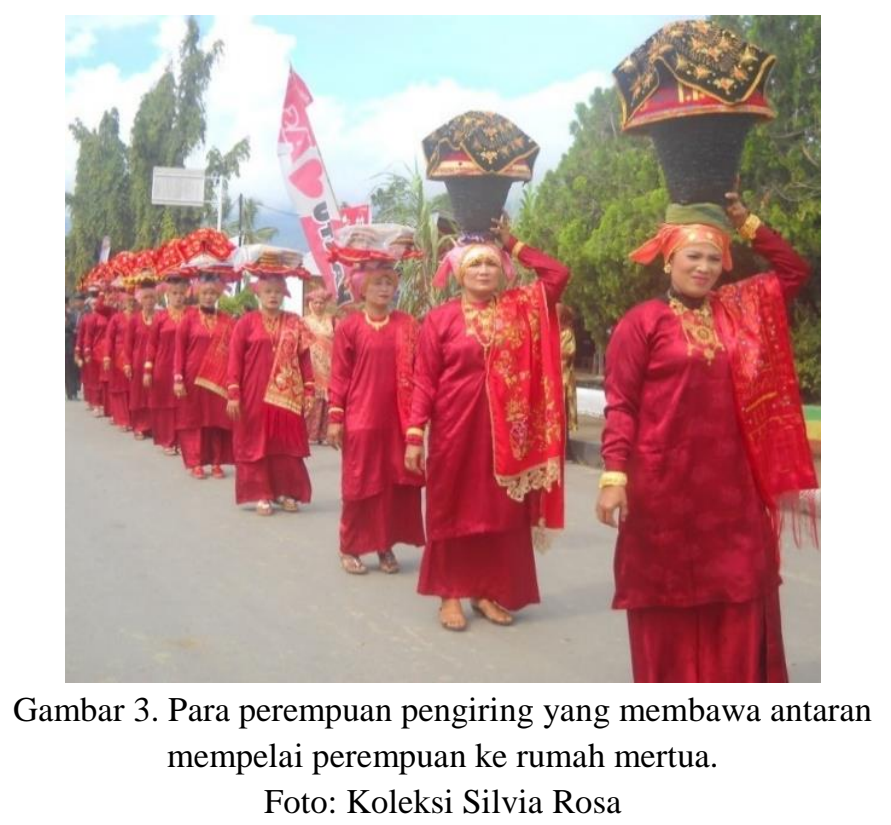

Kostum yang dipakai oleh perempuan pengiring pelaksanaan Tradisi Tunduak tampak satu warna, yaitu merah. Sementara mempelai perempuan dan lelaki mengenakan pakaian mempelai khas adat orang Solok, baju batabua jo basiba berwarna hitam, dilengkapi dengan kain salodang, topi jo bungo sanggua. Baju batabua (baju bertabur) adalah baju pesta adat yag meriah yang dihiasi dengan taburan benang emas. Baju basiba adalah baju kurung yang diberi sambungan di sisi bagian kiri dan kanan badan agar baju itu tidak terkesan ketat, melainkan tampak longgar. Kain salodang adalah kain selendang khusus yang dipakai oleh mempelai perempuan. Topi jo bungo sanggua (topi dan bunga sanggul) adalah hiasan kepala yang dipakai oleh mempelai perempuan.

Gambar 4 berikut ini adalah seorang mempelai perempuan yang memakai baju batabua jo basiba berwarna hitam dalam pelaksanaan Tradisi Tunduak. 


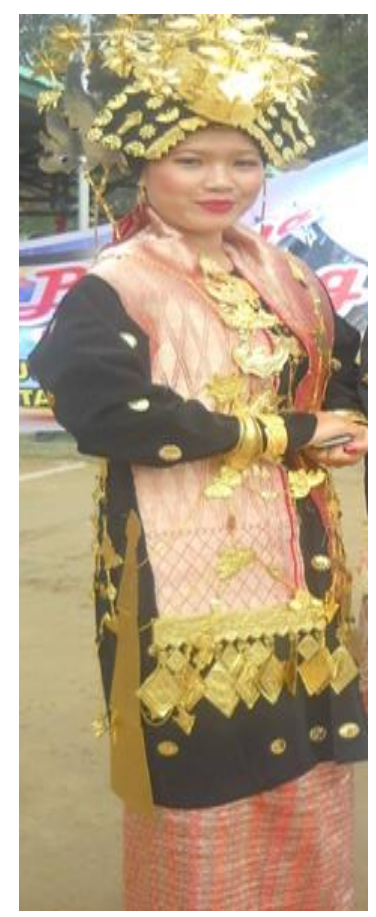

Gambar 4. Pakaian mempelai perempuan dalam pelaksanaan Tradisi Tunduak.

Foto: Koleksi Silvia Rosa

Jenis alek yang dilaksanakan juga berpengaruh pada jenis pakaian mempelai perempuan dan para perempuan pengiring pelaksanaan Tradisi Tunduak. Artinya, besar kecil alek dan ruang lingkup alek juga menentukan jenis pakaian mempelai perempuan dan para pengiring pelaksanaan Tradisi Tunduak ini. Bahkan, asal-usul mempelai pun turut memberi pengaruh pada pemilihan pakaian mempelai dan para pengiringnya. Apabila mempelai tidak sama-sama berasal dari Solok, melainkan ada salah satu dari mereka yang berasal dari luar Solok, maka yang akan dipakai dalam acara adat itu adalah adat keluaran, dan itu berpengaruh pada jenis pakaian mempelai dan para pengiring pelaksanaan Tradisi Tunduak. Dengan demikian, tampak betapa ketatnya orang Solok dalam merencanakan persiapan pelaksanaan sebuah prosesi perkawinan di Solok, termasuk pelaksanaan Tradisi Tunduak ini.

\section{Pembahasan}

Tradisi Tunduak selalu dilakukan di berbagai tempat di Solok. Hampir setiap akhir pekan bahkan di luar hari Minggu pun (biasanya pada hari balai) tampak arak-arakan prosesi tradisi ini beriring-iringan di tepi jalan raya. Semua mempelai perempuan melakukan tradisi ini kepada mertuanya, apabila ia menikah dengan lelaki yang juga berasal dari Solok. Tradisi ini sudah dilakukan sejak dulu hingga kini. Bertolak pada konsep Barthes (1993), maka tradisi ini telah menjadi mitos kolektif yang sukses dalam masyarakat Solok. Kepatuhan mempelai perempuan dan kerabatnya untuk melaksanakan tradisi ini sehari dan atau dua hari setelah pesta perkawinan adat dilakukan, menandai kekhawatiran kerabat mempelai perempuan akan dipandang tidak paham ada jika tidak melaksanakannya.

Makna yang tersimpan di balik semua penanda artifisial yang melekat pada prosesi pelaksanaan Tradisi Tunduak ini, baik terkait dengan orang yang terlibat, barang bawaan yang 
diangkut di dalam katidiang hitam di atas kepala, susunan perempuan pengiring dalam barisan Tradisi Tunduak, maupun terkait dengan waktu pelaksanaan, biaya yang dipikul oleh kerabat mempelai perempuan, kostum yang dikenakan oleh mempelai perempuan dan para pengiringnya, mengandung gagasan bahwa semua penanda-penanda artifisial dan visual itu mengacu pada satu konsep yang penuh untuk pemuliaan posisi mempelai lelaki dan kerabatnya. Pemuliaan itu dilakukan demi pencapaian satu tujuan harmonisasi hubungan menantu perempuan dengan mertuanya, dan sekaligus semua kerabat karib kedua belah pihak.

Sikap itu ditopang oleh nilai-nilai agamis yang bersumber dari ajaran Islam. Tidak terbantahkan bahwa agama mayoritas yang dianut oleh orang Minangkabau adalah agama Islam. Bahkan, dinyatakan dengan tegas melalui sebuah mamangan adat Minangkabau bahwa agama Islam menyempurnakan adat Minangkabau. Mamangan itu berbunyi sebagai berikut "adat basandi syarak, syarak basandi kitabullah" (adat bersendi agama, agama bersendi kitabullah). Maksud dari mamangan adat ini bahwa aturan adat Minangkabau dikuatkan oleh agama, aturan agama yang menguatkannya itu adalah agama yang mempunyai kitab suci Al Quran (kitabullah). Implikasi ideologis dari pelaksanaan seluruh rangkaian kegiatan Tradisi Tunduak yang dilakukan oleh orang Solok, menyuarakan sebuah kekuatan patriarki yang melesat masuk dengan alamiah ke dalam budaya orang Minangkabau yang cenderung bernuansa matriarki.

Hanya saja, prosesnya berlangsung amat manis, lembut, terkesan sangat alamiah sehingga tidak menyisakan pertanyaan sedikit pun bagi orang Solok tentang asal-usul pelaksanaan Tradisi Tunduak tersebut. Bagi orang Solok, pelaksanaan tradisi tersebut adalah sebuah keniscayaan yang diwariskan dari nenek moyang, yang mesti dirayakan dengan ritual adat Minangkabau yang penuh sesak dengan atribut-atribut kebudayaan Minangkabau yang matrilineal. Kampia siriah yang dibungkus kain berwarna merah dan dibawa oleh Tuo Tunduak di atas kepalanya merupakan penanda visual yang melegalisasi kegiatan tersebut sebagai kegiatan perayaan adat Minangkabau yang an sich.

Orang Solok tidak sempat mempertanyakan sejak kapan tradisi itu mereka rayakan. Sejak adat dinyatakan disempurnakan oleh agama Islam-kah? Bagaimanakah bentuk perayaan itu sebelum agama Islam masuk ke tanah Minangkabau, khususnya ke kawasan Solok? Adakah Tradisi Tunduak dirayakan oleh masyarakat Solok? Apabila tidak, lalu apa artinya pelaksanaan Tradisi Tunduak bagi masyarakat Solok? Serangkaian pertanyaan semacam ini tidak sempat mencuat dari alam bawah sadar orang Solok karena mitos telah sukses menghipnotis masuk ke alam pikiran kolektif masyarakat Solok terkait pemuliaan mempelai lelaki dan kerabatnya tersebut.

Sementara, orang Solok amat paham bahwa seorang menantu lelaki dalam lingkup kerabat pihak perempuan adalah tamu yang posisinya diibaratkan bagai abu di ateh tunggua (abu di atas tunggul), artinya sebuah debu yang amat mudah diterbangkan oleh angin. Bukankah kondisi ini menjadi sesuatu yang kontradiktif? Memuliakan posisi orang yang posisinya diibaratkan mudah diterbangkan oleh angin, bahkan angin semilir pun. Akan tetapi, di sanalah kelihaian mitos merangsek masuk ke alam bawah sadar pikiran kolektif sehingga kekuatan subversif itu tidak tampak sebagai ancaman bagi budaya asli yang dimasuki oleh mitos tersebut. 


\section{SIMPULAN}

Secara semiologi, pelaksanaan Tradisi Tunduak yang dilakukan oleh mempelai perempuan dan kerabatnya kepada ibu mertua dengan membawa serangkaian atribut persembahan, berimplikasi ideologis, mistis, dan konstruktif. Bias kekuatan budaya patriarki menyelinap masuk mencengkeram alam pikiran dan budaya Minangkabau yang matriarki.

Hal yang dapat dimaknai dari fenomena ini adalah betapa kemurnian ideologi matriarki itu akan selalu "dikejar", dirongrong, dan diubah oleh ideologi patriarki untuk menjadi sesuai dan sempurna sebagaimana yang dikehendaki oleh sebuah subversi budaya tersebut. Matrilinieal tidak akan dapat bertahan dalam kemurnian, kealamiahannya, selagi patrilineal masih kencang mencengkeram masuk ke alam bawah sadar kolektif.

\section{DAFTAR PUSTAKA}

Asmaniar, A. 2018. "Perkawinan Adat Minangkabau". Binamulia Hukum, 7 (2):131-140. https://doi.org/10.37893/jbh.v7i2.23

Azhari, F., Muttaqien, Z., \& Kurdi, S. 2013. "Motivasi Perkawinan Endogami pada Komunitas Alawiyyin di Martapura Kabupaten Banjar". Mu'adalah: Jurnal Studi Gender Dan Anak, 1 (2):85-102.

Barthes, R. 1993. Mythologies (translated). London: Paladin.

Darussalam, A. 2017. "Pernikahan Endogami Perspektif Islam dan Sains". Tahdis: Jurnal Kajian Ilmu, $8 \quad$ (1):1-20. Retrieved from http://journal.uinalauddin.ac.id/index.php/tahdis/article/download/3997/3695

Herviani, F. 2019. "Larangan Menikah Sesuku dalam Adat Minangkabau Perspektif Saddu Al- Dzarî‘ ah: Studi di Nagari Lareh Nan Panjang Kota Padang Panjang", 3 (2):1-12.

Khairani, R., \& Fitriani, E. 2020. "Respons Orang Minangkabau terhadap Kasus Kawin Sasuku". Culture \& Society, 1 (4):218-225.

Nuryani. 2012. Latar Belakang dan Dampak Perkawinan Endogami di Desa Sidigede Kecamatan Welahan Kabupaten Jepara. Semarang: Unnes.

Parwesi, N.K.Y. 2012. Perkawinan Endogami di Kalangan Masyarakat Tenganan Pegringsingan di Kabupaten Karangasem Bali. Universitas Gadjah Mada. Retrieved from

http://etd.repository.ugm.ac.id/index.php?act=view\&buku_id=53974\&mod=penelitian _detail\&sub=PenelitianDetail\&typ=html

Putriyah, N. 2016. "Perkawinan Eksogami: Larangan Perkawinan Satu Datuak di Nagari Ampang Kuranji, Sumatera Barat. Al-Ahwal: Jurnal Hukum Keluarga Islam, 8 (2):175. https://doi.org/10.14421/ahwal.2015.08205

Rosa, S., Gayatri, S., Awwali, M., Hasanuddin, \& Anwar, K. 2010. Adat dan Budaya Kota Solok (1st ed.). Solok: Pemerintah Daerah Kota Solok.

Wardani, N.P.Y., Pursika, I.N., \& Adnyani, N.K.S. 2013. "Pelaksanaan Perkawinan Endogami pada Masyarakat Bali Aga di Desa Adat Tenganan Pegringsingan Kecamatan Manggis Kabupaten Karangasem". Pendidikan Kewarganegaraan, 1 (4). 